\title{
Program Employee Gathering “Satukan Hati Selaraskan Tujuan” Dalam Menjalin Hubungan Baik Karyawan
}

\author{
Pramelani $^{1}$, Ayu Lestari² \\ Universitas Bina Sarana Informatika \\ 1e-mail: pramelani@gmail.com \\ 2e-mail: lestaryayu16@gmail.com
}

Cara Sitasi: Pramelani, Lestari, A. (2019). Program Employee Gathering “ Satukan Hati Selaraskan Tujuan ” Dalam Menjalin Hubungan Baik Karyawan. Jurnal Komunikasi, 10(1), 42-47.

\begin{abstract}
Employees are company assets. Therefore employees are needed for the growth of a company. Therefore, every employee must be able to work together, compact so that work productivity can increase. Establishing good relationships between employees, always maintained for each company. To further strengthen this relationship, the company needs to hold an employee gathering program intended for all workers in the company. In addition to being able to refresh themselves but also can build compactness in work the better. Thus, the researcher wants to know about the employee gathering program conducted by PT Kurnia Mitra Selaras in establishing good employee relations with the theme "Unite Hearts in harmony with Goals". The method used is descriptive qualitative. And the results of the research stated that the employee gathering program "Unite Hearts in harmony with the Goals" in establishing employee relations held on Saturday Sunday, 3-4 February 2018 at Villa Teratai, Lembang, Bandung can run successfully where the program is in accordance with the event rundown participants felt happy to have a good effect on employee relations where the length of time they rarely communicate among fellow employees because of their respective work activities.
\end{abstract}

Keywords: employee gathering, employee relations

\section{PENDAHULUAN}

Dalam suatu perusahaan sangat penting adanya kebersamaan ataupun kerjasama yang baik antar para pekerja yang ada di dalam organisasi tersebut. Dengan adanya kekompakan dalam sebuah tim di perusahaan memberikan dampak yang positif bagi perusahaan yakni dalam hal peningkatan produktivitas kerja.

Tidak sedikit perusahaan yang menerapkan program employee gathering sebagai suatu kegiatan rutin karena dirasakan manfaat dari employee gathering tersebut. Salah satunya yakni yang dilakukan oleh PT Swakarya Insan Mandiri (SIMGroup) dimana menurut Anta Ginting, Direktur SIMGroup mengatakan bahwa employee gathering yang diadakan di luar kantor bersama karyawan dapat merefresh diri serta dapat membangun kekompakkan dalam bekerja semakin baik. (Tribunnews.com, 2018)
Padatnya aktivitas pekerjaan yang dibebankan oleh karyawan dan kurangnya komunikasi dengan sesama karyawan menyebabkan adanya kejenuhan sehingga menurunkan efektivitas pekerjaan yang terjadi pada PT Kurnia Mitra Selaras. Perusahaan ini bergerak di bidang jasa transportasi logistik darat yang berlokasi di Jl. Terusan I Gusti Ngurah Rai No. 9 Pondok Kopi, Jakarta Timur.

Untuk mengatasi permasalahan yang dihadapi tersebut, humas PT Kurnia Mitra Selaras mengadakan acara employee gathering tanggal 3-4 Februari 2018 di Villa Teratai, Lembang, Bandung dengan tujuan meningkatkan keakraban dan keharmonisan antar karyawan.

Oleh karena itu, penulis tertarik untuk mengetahui program employee gathering "Satukan Hati Selaraskan Tujuan” dalam menjalin hubungan baik karyawan. 
Tujuan dari riset ini yakni untuk mengetahui program employee gathering yang diadakan oleh PT Kurnia Mitra Selaras dalam menjalin hubungan baik antar karyawan.

Sedangkan manfaat yang dapat diambil adalah bagi mahasiswa dapat digunakan sebagai referensi yang berkenaan dengan program employee relations, dan dapat juga bermanfaat untuk masukan perusahaan yang sedang menjaga serta meningkatkan hubungan karyawan.

Riset ini berkenaan dengan program humas yang dlakukan oleh PT Kurnia Mitra Selaras. Lebih lanjut, definisi humas adalah bentuk komunikasi terencana agar dapat mencapai tujuan berdasarkan pada saling pengertian.(Suryani, 2015)

Humas tersebut memiliki fungsi-fungsi yang terdiri dari menulis, hubungan media, perencanaan, konsultasi, penelitian, publisitas, komunikasi pemasaran, hubungan pelanggan, hubungan komunitas, hubungan karyawan, hubungan pemerintah, hubungan investor, humas khusus, urusan publik dan manajemen isu, serta pembuatan website dan monitoring. Salah satu hubungan diantara fungsi humas adalah hubungan antar karyawan dimana menjalin hubungan baik dengan karyawan perusahaan dengan berkomunikasi yang berhubungan dengan publik internal. (Febriansyah, 2014b)

Dalam menjalankan tugasnya, humas memiliki program-program yang ditetapkan. Definisi dari program humas merupakan salah satu usaha yang dilaksanakan untuk menjalin hubungan baik secara internal maupun eksternal agar tercipta citra positif di mata publik. (Febriansyah, 2014b)

Humas memiliki salah satu fungsi yakni membangun hubungan dengan publik internal dan publik eksternal. Peran humas internal sebagai penghubung antara management dengan para karyawan supaya tidak terjadi misscomminucation sehingga dalam bekerja menjadi nyaman dan karyawan menjadi loyalitas. (Mahfuzhah \& Anshari, 2018)

Dijelaskan pula bahwa humas merupakan fungsi manajemen untuk membangun, mempertahankan serta menjaga hubungan semakin harmonis yang berguna bagi organisasi dan publik. (Hakiki, 2018). Atau dapat dikatakan bahwa dalam setiap programnya, humas juga menjalankannya tidak lepas dari unsur manajemen.

Program humas tersebut berkaitan dengan employee relations. Pengertian employee relations yakni sekelompok orang yang masih bekerja dalam perusahaan yang memiliki fungsional, organisasi serta jenis pekerjaan yang jelas. (Ningsih \& Puspitosari, 2018)
Kegiatan yang dilakukan perusahaan berupa employee gathering. Definisi employee gathering merupakan mekanisme yang diadakan perusahaan dengan tujuan menjaga serta memperkuat hubungan, terutama para karyawan.(Febriansyah, 2014a)

\section{METODOLOGI PENELITIAN}

Teknik pengumpulan data dilakukan dengan :

1. Observasi

Kegiatan mendapatkan informasi untuk keperluan penyajian secara real gambaran kejadian atau peristiwa untuk menjawab penelitian.

2. Wawancara

Pengumpulan informasi dengan tanya jawab secara tatap muka atau tanpa tatap muka melalui media telekomunikasi.

3. Dokumentasi

Teknik pengumpulan data dengan cara mencari dari data-data yang tersimpan dalam bentuk dokumentasi. (Yulanda, Devi, \& Putri, 2017)

Di samping itu, penulis juga melakukan studi kepustakaan dimana pengumpulan data teoritis dari buku-buku, jurnal, internet dan literature agar memperoleh teori-teori serta bahan-bahan untuk keperluan penelitian. (Widayanto, Suleman, \& S, 2017)

Metode analisa data dalam penelitian ini adalah metode deskriptif kualitatif. Pengertian dari metode deskriptif adalah mendeskripsikan atau menggambarkan secara sistematis fakta-fakt, sifatsifat, hubungan antar fenomena yang diteliti. (Fitrianti, Hidayat, Suhadi, \& Tyaswara, 2014)

Sedangkan penelitian kualitatif merupakan penelitian deskriptif dan cenderung menggunakan analisa.(Leliana, 2015).

Dalam pencarian data, riset ini wawancara ke key informan dan informan. Key informan adalah "Orang utama yang merupakan kunci diharapkan menjadi narasumber atau informan kunci dalam suatu penelitian.” Dan informan adalah "seseorang yang bertindak sebagai pembantu peneliti, tetapi ia berasal dari atau menjadi anggota kelompok yang diteliti.” (Maudi \& Susilowati, 2018)

Key informan dalam riset ini yakni Hendra Suhenda selaku Humas PT Kurnia Mitra Selaras, dan dua informan yang merupakan peserta program employee gathering yaitu Ahmad Fiqri Baihaqi selaku karyawan di bagian finance serta Indri Yulianingsih adalah karyawan di bagian purchasing. 


\section{HASIL DAN PEMBAHASAN}

Dalam kegiatan employee gathering yang diadakan oleh PT Kurnia Mitra Selaras memiliki perencanaan dimana dilihat dari analisa situasi bahwa karyawan dalam perusahaan tersebut kurangnya komunikasi antara pimpinan dengan karyawan maupun antar sesama karyawan.

\section{Perencanaan}

Program ini sudah direncanakan oleh PT Kurnia Mitra Selaras dengan adanya rapat internal di kantor perusahaan pada hari Senin, 02 April 2017 yang membahas mengenai konsep kegiatan employee gathering yang berlangsung selama 2 hari pada hari Sabtu- Minggu, 3-4 Februari 2018 di Villa Teratai, Lembang, Bandung. Dalam rapat tersebut pun sudah ditetapkan susunan panitia, tema, tujuan kegiatan sehingga dibuatkan proposal. Kemudian, dalam persiapannya, para panitia melakukan survey lokasi acara pada tanggal 9-10 Juni 2017 serta mengkoordinasikan dengan pihak-pihak yang berkaitan dengan acara.

Target khalayak yang dituju adalah perwakilan pimpinan, pengurus Ikatan Karyawan KUMIS, dan perwakilan karyawan yang sudah terdaftar dalam proposal kegiatan yakni terdapat 54 orang.

Berdasarkan wawancara dengan Hendra Suhenda bagian Humas PT Kurnia Mitra Selaras, pesan yang disampaikan adalah "Satukan hati selaraskan tujuan" dimana karyawan selalu terjaga tali persaudaraan satu sama lain..

Strategi yang dilakukan adalah mengajak seluruh karyawan secara persuasif mengumpulkan karyawan dan membuka pendaftaran untuk karyawan yang akan ikut acara yang kemudian data tersebut dilaporkan ke panitia acara. Sedangkan taktiknya yakni dengan membuat acara employee gathering dengan berbagai hiburan seperti adanya perlombaan, musik, maupun doorprize.

Media yang digunakan untuk mengundang seluruh karyawan agar terlibat melalui surat undangan, whatsapp grup, mading di setiap divisi, ataupun brosur, spanduk.

Pelaksanaan

Anggaran yang dikeluarkan agar terlaksana acara employee gathering tersebut sebesar kurang lebih 27 juta.

Pelaksanaan acara employee gathering diadakan pada hari Sabtu-Minggu, 3-4 Februari 2018 di Villa Teratai, Lembang, Bandung terselenggara sesuai dengan rundown acara sebagai berikut:

Tabel 1. Rundown Program Employee Gathering

Tanggal 3-4 Februari 2018, Villa Teratai Lembang

\begin{tabular}{|c|c|c|}
\hline Waktu & Nama Acara & $\begin{array}{c}\text { Penanggung } \\
\text { Jawab }\end{array}$ \\
\hline \multicolumn{3}{|c|}{ Hari Sabtu, 3 Februari 2018} \\
\hline $07.00-11.00$ & Perjalanan & \\
\hline $11.00-12.00$ & $\begin{array}{l}\text { Sampai Villa Teratai } \\
\text { (Pembagian Kamar) }\end{array}$ & Panitia \\
\hline $13.00-14.00$ & Isoma & \\
\hline $14.00-17.00$ & $\begin{array}{l}\text { Foto All Team + } \\
\text { Team Building }\end{array}$ & \\
\hline $60^{\prime}$ & Game 1 & \\
\hline $60^{\prime}$ & Game 2 & \\
\hline $60^{\prime}$ & Game 3 & \\
\hline $17.00-19.00$ & $\begin{array}{lll}\text { Istirahat } \\
\text { Malam }\end{array}$ & \\
\hline $19.30-21.30$ & Acara Malam & \\
\hline $5^{\prime}$ & $\begin{array}{l}\text { Pembukaan (Kumis } \\
\text { Icon) }\end{array}$ & MC \\
\hline $5^{\prime}$ & Sambutan Ketua IKK & Ketua IKK \\
\hline $5^{\prime}$ & $\begin{array}{l}\text { Sambutan } \quad \text { Ketua } \\
\text { Koperasi }\end{array}$ & $\begin{array}{l}\text { Ketua } \\
\text { Koperasi }\end{array}$ \\
\hline $10^{\prime}$ & $\begin{array}{l}\text { Laporan IKK \& } \\
\text { KASS }\end{array}$ & \\
\hline $60^{\prime}$ & Tanya Jawab & \\
\hline $21.30-23.00$ & $\begin{array}{l}\text { Ramah Tamah } \\
\text { (Organ-BBQ) }\end{array}$ & \\
\hline
\end{tabular}

Hari Minggu, 4 Februari 2018

\begin{tabular}{lll}
\hline $07.00-09.00$ & Senam \& Sarapan & \\
\hline $09.00-11.00$ & Prepare Pulang & Panitia \\
\hline $11.00-12.00$ & $\begin{array}{l}\text { Makan Siang (Nasi } \\
\text { Kotak) }\end{array}$ \\
\hline 13.00 - Selesai & Pulang & \\
\hline
\end{tabular}

Sumber : Dokumentasi Humas PT Kurnia Mitra Selaras (2018)

Berikut foto-foto pada pelaksanaan berlangsung:

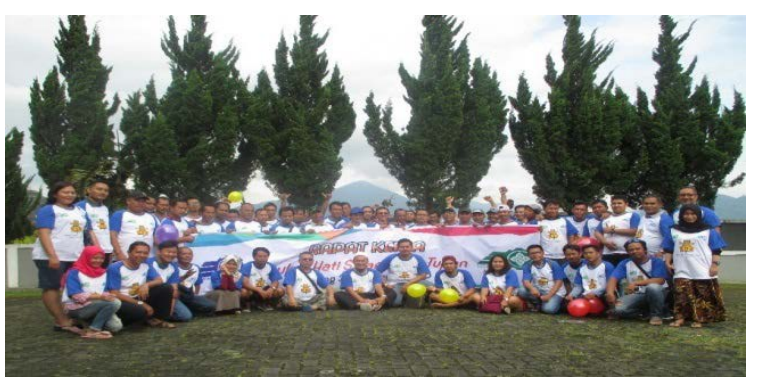

Sumber : Dokumentasi Humas PT Kurnia Mitra Selaras (2018)

Gambar 1. Foto Bersama Seluruh Peserta Acara Employee Gathering di Villa Teratai Tahun 2018 


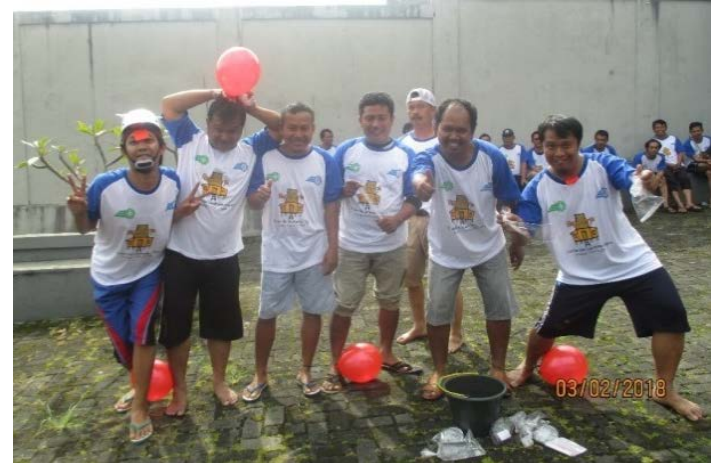

Sumber : Dokumentasi Humas PT Kurnia Mitra Selaras (2018)

Gambar 2. Foto Kekompakan Peserta Dalam Lomba di Acara Employee Gathering di Villa Teratai Tahun 2018

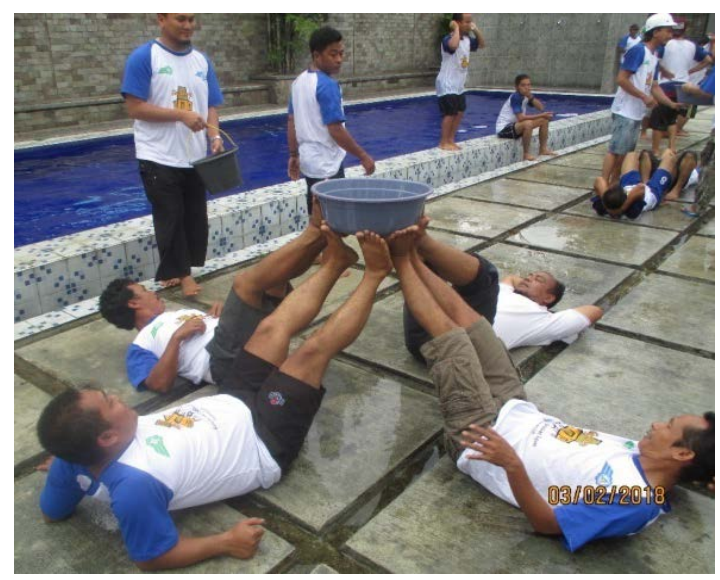

Sumber: Dokumentasi Humas PT Kurnia Mitra Selaras (2018)

Gambar 3. Foto Karyawan Dalam Games Acara Employee Gathering di Villa Teratai Tahun 2018

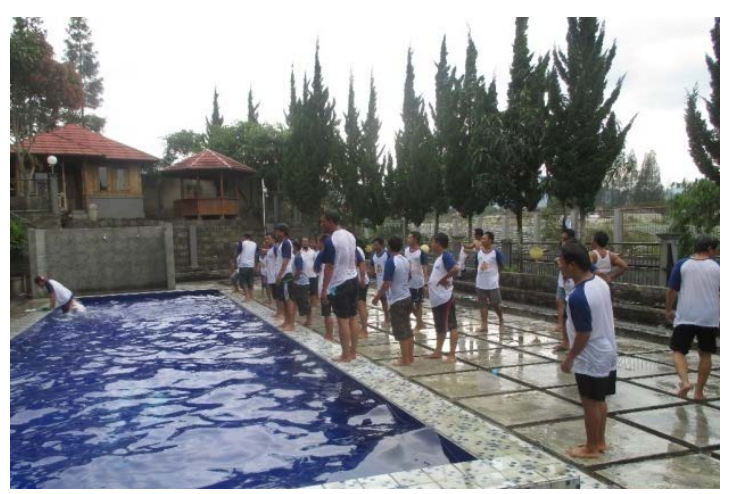

Sumber: Dokumentasi Humas PT Kurnia Mitra Selaras (2018)

Gambar 4. Foto Games di Kolam Renang Villa Teratai Tahun 2018

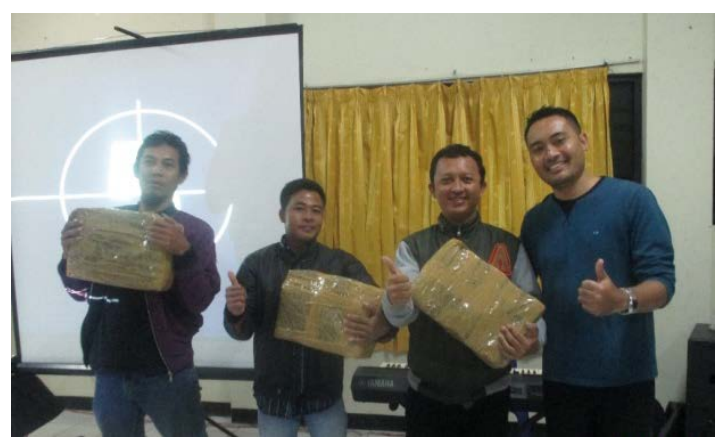

Sumber : Dokumentasi Humas PT Kurnia Mitra Selaras (2018)

Gambar 5. Foto Pembagian Doorprize Dalam Acara Employee Gathering di Villa Teratai Tahun 2018

\section{Evaluasi}

Dari pelaksanaan yang telah diselenggarakan selama dua hari dari tanggal 3-4 Februari 2018 di Villa Teratai, evaluasi yang dapat diambil sebagai berikut: Berdasarkan penuturan dari Hendra Suhenda bahwa program tersebut berhasil sukses apabila dilihat dari antusiasme para karyawan yang berpatisipasi. Acara tersebut berjalan sesuai dengan rundown acara yang telah ditetapkan meskipun ada beberapa kendala yang dihadapi. Di samping itu, hubungan karyawan antar bagian dapat menjadi lebih erat dan semakin kompak dalam kerjasama tim di lingkungan kerja sehingga berdampak positif pada pelayanan ke konsumen.

Hal tersebut didukung oleh para peserta yang ikut dalam program employee gathering yakni Ahmad Fiqri Baihaqi, salah satu informan, yang mengungkapkan kesan perasaan senang dengan diadakannya acara tersebut karena dibawakan secara professional dengan penuh keceriaan, kebersamaan, serta memiliki makna kebersamaan. Kegiatan tersebut selain untuk peserta yang ikut cukup tinggi dan acara dapat berjalan sesuai dengan rundown acara yang telah ditetapkan. Hal tersebut pun disampaikan oleh peserta yang turut hadir yakni Ahmad Fiqri Baihaqi, salah satu informan, yang mengungkapkan kesan perasaan senang dengan diadakannya acara tersebut karena dibawakan secara professional dengan penuh keceriaan, kebersamaan, serta memiliki makna kebersamaan. Kegiatan tersebut selain untuk refreshing dari rutinitas pekerjaan, dapat menjalin siraturahmi dengan karyawan agar komunikasi dan kerjasama selalu terjaga. Di samping itu, peserta lainnya yang ikut hadir dalam program employee gathering adalah Indri Yulianingsih bagian purchasing PT Kurnia Mitra Selaras juga mengatakan merasa senang telah diselenggarakan kegiatan tersebut dimana terdapat semangat baru untuk bekerja kembali dan mempunyai efek yang baik bagi hubungan karyawan dimana lamanya jarang berkomunikasi antar sesama karyawan karena kesibukan pekerjaan masingmasing 


\section{KESIMPULAN}

Dari hasil penelitian dapat disimpulkan bahwa:

Employee gathering merupakan salah satu program employee relations yang dilakukan oleh perusahaan yang sangat penting dalam menjalin komunikasi baik antar karyawan. Dan PT Kurnia Mitra Selaras pun telah melakukan kegiatan employee gathering di Bandung dan hasilnya sangat efektif dimana peningkatan kebersamaan antara manajemen dengan karyawan. Dan kegiatan ini menjadi kegiatan rutin tiap tahun.

Saran yang dapat diberikan untuk PT Kurnia Mitra Selaras yaitu:

1. Disarankan bahwa humas PT Kurnia Mitra Selaras dapat meningkatkan acara employee gathering lebih variatif, menghibur dan bermanfaat dengan suasana yang berbeda setiap tahun agar dapat menambah semangat para karyawan.

2. Perusahaan dapat membuat kegiatan employee gathering dalam bentuk seminar, training, workshop ataupun kegiatan ta'lim setiap bulan untuk menambah keakraban antar karyawan.

3. Diharapkan setelah dilakukannya setiap kegiatan employee gathering selalu dilakukan evaluasi terhadap program yang dijalankan agar dapat menjadi pedoman untuk kegiatan berikutnya

\section{REFERENSI}

Febriansyah, M. R. (2014a). Employee Gathering Perusahaan Global Enterpreneur Teknologi Solutions Dalam Menjalin Hubungan Yang Baik Antar Karyawan. SNIPTEK, 1-8.

Febriansyah, M. R. (2014b). Program Corporate Social Responsibility Oleh Humas PT Radio Suara Leo Dalam Meningkatkan Kepedulian Terhadap Yayasan Anak Yatim Di Wilayah Cirebon. SNIPTEK, 9-14.

Fitrianti, A., Hidayat, D., Suhadi, M., \& Tyaswara, B. (2014). Representasi Kampung Seni Dago Sebagai Objek Wisata Kota Bandung. Jurnal JIKA, 1 Nomor 2.

Hakiki, S. N. (2018). Kepemimpinan Kiai Sebagai Personal Branding Pesantren Dalam Perspektif Public Relation (Humas). FIKROTUNA: Jurnal Pendidikan Dan Manajemen Islam, 8 Nomor 2, 891-903. Retrieved from http://ejournal.kopertais4.or.id/madura/index.p hp/fikrotuna/article/view/3287/2436

Leliana, I. (2015). Human Relations Dalam Peningkatan Kualitas Kinerja Dan Kreatifitas Karyawan Di SUDIN Komunikasi, Informasi
Dan Kehumasan Walikota Jakarta Timur. SNIPTEK, 23-31.

Mahfuzhah, H., \& Anshari. (2018). Media Publikasi Humas Dalam Pendidikan. Al-Tanzim: Jurnal Manajemen Pendidikan Islam, 2, 137-149.

Maudi, E., \& Susilowati. (2018). Strategi Koperasi Karya Mandiri Dalam Memperkenalkan Product Knowledge Melalui Event Gowes Pesona Nusantara. Jurnal Komunikasi, 9(1), 31-38.

https://doi.org/https://doi.org/10.31294/jkom.v 9i1

Ningsih, A. S. R., \& Puspitosari, R. (2018). Peran Public Relations Internal Pada Kegiatan Employee Relations Dalam Meningkatkan Kinerja Karyawan PT XL AXIATA TBK. PANTAREI, 2. Retrieved from http://jom.fikom.budiluhur.ac.id/index.php/Pan tarei/article/view/198

Suryani, I. (2015). Program Corporate Social Reponsibility Peningkatan Kesejahteraan \& Kontribusi Sosial Kepada Masyarakat Oleh Kementerian Sosial RI. SNIPTEK, 32-37.

Tribunnews.com. (2018, November 28). Employee Gathering Serentak di Tiga Kota dan Launching Gawe.Id Artikel ini telah tayang di Tribunnews.com dengan judul Employee Gathering Serentak di Tiga Kota dan Launching Gawe.Id , http://www.tribunnews.com/bisnis/2018/11/28/ employee-gathering-serentak.

Tribunnews.Com. Retrieved from http://www.tribunnews.com/bisnis/2018/11/28/ employee-gathering-serentak-di-tiga-kota-danlaunching-gaweid

Widayanto, A., Suleman, \& S, I. A. (2017). Rancang bangun aplikasi kategori bahasa untuk tuna wicara berbasis android 1). Evolusi, 5(2), 18$26 . \quad$ Retrieved from http://ejournal.bsi.ac.id/ejurnal/index.php/evolu si/article/view/2845/1849

Yulanda, G., Devi, E., \& Putri, H. (2017). Strategi Guest Relation Officer Dalam Penanganan Tamu Yang Menunggu Pelayanan Di Hotel Santika Premiere Yogyakarta. Jurnal Khasanah Ilmu, 8(1), 20-30. Retrieved from http://ejournal.bsi.ac.id/ejurnal/index.php/khasa nah/article/view/1413/1267

\section{PROFIL PENULIS}

Pramelani, lulusan Magister Manajemen (MM) Program Pasca Sarjana Universitas Bina Sarana Informatika Bandung pada tahun 2015 dan selalu aktif dalam penulisan buku ataupun jurnal, aktif 
dalam pengajaran, organisasi non komersil serta seminar.

Ayu Lestary, lulusan Fakultas Komunikasi dan Bahasa, Universitas Bina Sarana Informatika tahun ini, dan masih aktif bekerja di salah satu perusahaan swasta di Jakarta. 